\title{
Independent Contingency and Token Economy at Recess to Reduce Aggression
}

\author{
Jordan Yassine ${ }^{1} \cdot$ Leigh Ann Tipton-Fisler ${ }^{2}$ \\ Accepted: 11 February 2021 / Published online: 22 February 2021 \\ (C) This is a U.S. government work and not under copyright protection in the U.S.; foreign copyright protection may apply 2021
}

\begin{abstract}
School-wide behavior problems can vary significantly from structured to unstructured settings. Often problem behaviors can spike during unstructured times such as lunch and recess and the use of Tier 1 positive behavior interventions and supports (PBIS) can be used to reduce student behavior problems in these settings. Using a token economy as an independent group contingency, this study aimed to reduce student aggression in an elementary school during lunch/recess periods of the day. Students had the opportunity to earn school "dollars" during recess for demonstrating prosocial behaviors in which they were told could be exchanged for incentives at a student store (backup reinforcers). Across all grade levels, student levels of aggression were reduced between 50 and 100\% from baseline levels in a 3-month period. However, as effect sizes indicated, only some intervention groups showed significant reduction of aggression. Despite the limitation of access to backup reinforcers, we theorized that the effectiveness of the present intervention was due to socially mediated contingencies among student group members as a result of receiving dollars.
\end{abstract}

Keywords Recess intervention $\cdot$ Token economy $\cdot$ Independent contingency $\cdot$ Backup reinforcers

Classroom management is often an additional component to successful teaching that requires teachers to provide positive reinforcement for appropriate behavior in order to engage and support student learning (Sugai and Horner 2002). Typically, classroom management strategies are part of Tier 1 (universal) supports to increase on-task behavior and build positive student-teacher relationships (STR) (e.g., Fabiano et al. 2018; Floress et al. 2017). However, problem behaviors also occur during transitions and unstructured times when students are supervised less closely (Astor and Meyer 2001). Hence, such challenging behaviors can spike during unstructured settings such as recess and lunch resulting in a greater need for universal supports. The use of positive behavior interventions and supports (PBIS) across an entire campus are essential to increasing student prosocial behaviors in all school settings.

Leigh Ann Tipton-Fisler

1tipton@calstatela.edu

San Jacinto Unified School District, San Jacinto, CA, USA

2 California State University, Los Angeles, Charter College of Education, Los Angeles, CA, USA

\section{School-Wide PBIS}

As school-wide positive behavior interventions and supports (SWPBIS) are designed as multi-tiered approaches towards the reduction of behavior problems, the benefits of implementation include a reduction of overall office discipline referrals, decreased ethnic disproportionality in discipline, and improved overall school climate (Horner et al. 2009; SwainBradway et al. 2017). The multi-tiered model of SWPBIS is outlined similar to a public health model in which a Tier 1 universal level of support is designed to support all students with an easy-to-implement set of school-wide expectations (McIntosh et al. 2018). Tier 1 is also designed to be implemented across all school settings, including during structured and unstructured times. Tiers 2 and 3 of the SWPBIS model include more intensive and individualized interventions to support student social-emotional and behavioral needs. Some schools struggle with the implementation of Tier 1 (or universal) components of teaching and reinforcing expected behaviors and instead emphasize skill-deficits and negative consequences (Wright and McCurdy 2011). The use of a school-wide model is clearly beneficial for students meeting behavior expectations, even though fidelity of implementation for sustaining such a model can be challenging (Coburn et al. 2012). Regardless, the research literature has demonstrated 
that school teams incorporating data in the provision of staff feedback and training find better fidelity of intervention implementation (McIntosh et al. 2018). Due to the school-wide nature of universal support, Tier 1 SWPBIS interventions may show the lowest level of fidelity implementation in comparison to their other tiered counterparts. However, improvements can be made through structured coaching models for school staff and the use of more explicit interventions to teach behavior expectations (Codding et al. 2008). Group contingencies, as traditional Tier 1 interventions, often involve the identification of both positive and negative behaviors (Mesa et al. 2005; Murphy et al. 2007). Although the empirical literature has demonstrated that both reinforcement and punishmentbased interventions are effective tools in the reduction of maladaptive behaviors, the use of reinforcement-based procedures are recommended as first steps in intervention design and implementation (e.g., Behavior Analyst Certification Board 2014; Thompson and Iwata 2005). Thus, the current study implemented a token economy as a reinforcement-based intervention for Tier 1 intervention during unstructured time for aggressive behaviors.

\section{Behavior During Unstructured Time}

As Craig et al. (2000) found, problem behaviors have been observed to occur at a higher level on the school playground than in the classroom setting. Further, an estimated $50 \%$ of problem behaviors occur in non-classroom settings (Colvin et al. 1997). School staff responsible for students during unstructured settings typically lack essential training in behavior management strategies compared with classroom teachers (Astor and Meyer 2001). Such staff often resort to increased student supervision, which has been empirically shown to reduce problems from occurring but also requires a significant amount of staff support (e.g., Colvin et al. 1997; Lewis et al. 2000). However, concerns during unstructured time often escalate when supervisors are reliant upon students to selfmanage their own behaviors (McCurdy et al. 2009).

There is growing research to support the implementation of more structured support during recess. Shih et al. (2019) have explored the Remaking Recess (RR) intervention, which is a social skills invention geared towards improving peer relationships on the playground. The authors trained and supervised playground paraprofessionals to assist with the intervention. Paraprofessionals often have little training in behavior management skill, yet are responsible for large groups of students (Astor and Meyer 2001). However, paraprofessionals also have the greatest ability to implement change in peer relationships during unstructured school times, and this research found that students could improve their social relationships with peers through the RR intervention (Shih et al. 2019).
While the Good Behavior Game (GBG) is an intervention that has been routinely used in the classroom setting (e.g., Barrish et al. 1969), two studies have also used it in a recess setting to support increased physical activity (Galbraith and Normand 2017; Jung et al. 2005). In terms of implementation, Galbraith and Normand (2017) demonstrated the feasibility and acceptability of students working towards a reward and goal during recess. The GBG is often used as an interdependent group contingency. However, resistance occurred from teachers as a result of students demonstrating difficulty working in teams or exhibiting aggressive behaviors (Groves and Austin 2017). Further, the research on interdependent versus independent group contingencies have been mixed (e.g., Ennis et al. 2015; Theodore et al. 2004). To note, group contingencies often include a component in which an undesirable behavior by one student may result in an entire group of students contacting a consequence (e.g., dependent group contingencies). As Groves and Austin (2017) found, interdependent and independent GBG contingencies were similarly efficacious and decreased undesirable behavior. Further, group response patterns may be different than individuals considering that groups are composed of interchanging verbal behavior and social/cultural norms that can mediate operant contingencies in place (e.g., interlocking behavior contingencies; Glenn and Malott 2004; Krispin 2017). This grants a level of flexibility to both students and teachers on the preferred type of contingency implementation for school-wide or class-wide interventions. As such, young children have demonstrated some have difficulty understanding the expectations for points in certain group contingencies and may need more immediate consequences or visual reminders (Wahl et al. 2016).

\section{Token Economies}

Token economies are a reinforcement-based, individualized intervention in which a student can earn tokens (e.g., reward dollars) for demonstrating an appropriate behavior (Wolery et al. 1988). These tokens can then be exchanged for backup reinforcers, often from a student store, or in exchange for something from a teacher (Alberto and Troutman 2017; Soares et al. 2016). Important components of a token economy require an operational definition of the target behavior to be reinforced, student and teacher understanding of such procedures for reinforcement, and clear backup reinforcers and exchange of token systems (Ivy et al. 2017). The tokens can be distributed based on the occurrence of a target behavior on a ratio or interval schedule, as well as being paired with an explanation for why the student is being reinforced (e.g., verbal praise). Token economies have shown positive effects from decades of research both in and out of the classroom for increased rule following (McGoey and DuPaul 2000), cooperative play (Wolfe et al. 1983), and reduction of problem 
behaviors (Gaughan and Axelrod 1989). A variety of variables associated with the exchange can influence the effectiveness of a token economy including the schedule of exchange, magnitude of reinforcers, and degree of preference (e.g., Fiske et al. 2015; Bonfonte et al. 2020). However, it is common for some of the essential components to lack rigor or be skipped altogether during implementation due to social validity concerns (Ivy et al. 2017).

\section{Current Study}

The current study aimed to identify to what extent a token economy, as an independent group contingency intervention with students on a school playground, could reduce rates of aggression. The intervention was implemented due to more research being needed on feasible and resource-efficient Tier 1 interventions during unstructured periods outside of the classroom. Our hypothesis was that across all grade levels, a reduction in total instances of aggression would be observed and through an independent contingency, students would be socially motivated to earn the tokens or "school dollars."

\section{Methods}

\section{Participants and Setting}

An average total of 574 students across 3 different recess settings participated in the study across a 3-month period. Students were observed at an elementary school located in a rural school district in Southern California. The kindergarten recess consisted of a daily average of 87 kindergarten students. The first lunch recess included a daily average of 320 first and second grade students, and the second lunch recess included a daily average of 167 fourth and fifth grade students (grade 3 was a separate recess time that was not included in this intervention but we will refer to the upper grades as "grades 1-5" below). The kindergarten recess included an enclosed area consisting of a play structure, balls, and lunch tables. Both first and second lunch recesses included two square areas. One area measured included lunch benches and tables. The second area consisted of grass surrounded by a chain link fence. Students were monitored by nine campus paraeducators who were responsible for collecting data on behavioral occurrences and implementing the intervention. Each paraeducator was assigned to a zone for which to monitor and collect data.

\section{Spatial Assessment}

A large outside play area was segmented into 9 zones. Zones $1-5$ were used for play areas for students in grades $1-5$ only.
Zone 6 included an open grass area surrounded by a chained fence open to all students. Zones 7 and 8 were open only to kindergarten students and included the lunch tables and rubber surfaced play area. Zone 9 included a set of lunch tables on a concrete surface.

Paraeducators collected data on the frequency of aggression in each zone during each recess period. Using Google sheets, the spatial proportion of behavioral occurrences were analyzed in accordance with each zone, and classified according to conditional rate. Table 1 provides an overview of how the play area was divided into different zones for monitoring student behavior. The percentages of each zone were derived by dividing the average daily number of aggressive occurrences in a zone by the average daily number of aggressive occurrences for all zones combined. Using conditional formatting in google sheets, the zones in the image changed color according to a 5-point categorical scale of conditional rate. The range between the minimum and maximum proportions of occurrences for all zones was divided into five equal parts. Normal was classified as a proportion in a zone falling into the lowest $1 / 5$ of all zone proportions, Above Normal falling in the second lowest $1 /{ }_{5}$ of all proportions, Elevated as falling in the middle $1 / 5$ of all proportions, Highly Elevated as falling in the second highest $1 /{ }_{5}$ of proportions, and Critical as falling into the top $1 / 5$ of all proportions for all zones. Baseline data was collected across all Zones for each of the three recesses to identify the frequency of student aggression in each zone. Zones identified as critical were then the first targets for intervention after 12 school days of data. The zones intervened on included zones 7 and 8 (kindergarten recess areas), as well as zones 6 and 9 (lunch recess areas).

\section{Response Measurement, Interobserver Agreement, and Treatment Fidelity}

The paraeducators (i.e., lunch and recess aides) attended a 1hour training prior to the start of the study in which they were

Table 1. Spatial assessment

\begin{tabular}{llll}
\hline Zone & Grades & Layout & Frequency of aggression \\
\hline Zone 1 & Grades 1-5 & Play equipment & Normal \\
Zone 2 & Grades 1-5 & Blacktop & Normal \\
Zone 3 & Grades 1-5 & Blacktop & Normal \\
Zone 4 & Grades 1-5 & Tetherball & Elevated \\
Zone 5 & Grades 1-5 & Basketball court & Elevated \\
Zone 6 & Grades 1-5 & Grass field & Critical \\
Zone 7 & Kindergarten & Lunch tables & Critical \\
Zone 8 & Kindergarten & Play equipment & Critical \\
Zone 9 & Grades 1-5 & Lunch tables & Critical \\
\hline
\end{tabular}


trained on data collection procedures and progress monitoring. The staff training also included information on what active supervision during unstructured time entailed to effectively monitor student behaviors as recommended by Lewis et al. (2000). The observers used a handheld counter to collect data on occurrences of aggression in each zone during recess. Aggression was defined as movement of the body (including hands, arms, legs, or feet) against another individual. This included hitting, kicking, punching, and pushing. Our dependent variable was the frequency of aggression recorded per 5min interval (total frequency divided by 5 -min intervals).

A second observer collected interobserver agreement (IOA) for approximately $49 \%$ of school days and rotated among each of the paraeducators assigned to collect data in each zone. The observer was randomly assigned to overlap with a paraeducator during each day of baseline observation. Both the observer and paraeducator were stationed at the same location for shared view of students within each zone. IOA for each observation was calculated from the two observers by dividing the smaller number of recorded occurrences by the larger and multiplying by 100 . Results for IOA averaged $95 \%$ (range: 0-100\%) for all recess observers and zones. Treatment fidelity was collected for $32 \%$ of school days by recording the number of reward dollars correctly provided by each paraeducator and dividing by the number of prescribed dollars for each recess and zone. Mean treatment fidelity was $87 \%$ (range: 50-100\%) for kindergarten and first lunch recess periods.

\section{Experimental Design}

A concurrent multiple baseline design across three recess groups (kindergarten and two lunch recesses) was conducted. Each design consisted of a (a) baseline phase and (b) token economy and independent contingency phase. Intervention effect sizes were calculated using the visual analysis method of nonoverlap of all pairs (NAP; Parker and Vannest 2009).

\section{Baseline}

Data was collected on the number of occurrences of aggression under routine circumstances. Paraeducators were not instructed to differentially intervene throughout the phase. Occurrences of aggression were addressed in accordance with existing school policy and practice for business as usual during baseline. This included verbal reprimands, timeouts, and administrative discipline contingent on observed aggression. These procedures were instructed not to be used during the token economy other than when aggressive behaviors were observed that required separating two students for safety. The kindergarten recess lasted $20 \mathrm{~min}$ each school day, and for students in grades $1-5$, the lunch time was split for $40 \mathrm{~min}$ across the lunch tables and the play area (zones 6 and 9).

\section{Token Economy and Independent Contingency}

Prior to the start of the intervention, students were shown a video by a school administrator who introduced the reward "dollar" system, as part of the current school-wide PBIS initiative to reinforce students demonstrating appropriate behaviors and how the school currency could be used to buy incentives from a school store. The administrator also reviewed the behavior expectations for appropriate engagement during recess, and informed the students that they would have the opportunity to earn reward dollars for following those expectations. In the absence of aggression, positive behavior expectations included playing games "by the rules," using appropriate language and following adult directives (e.g., stopping when they're told, lining up). Playing by the rules is defined as behavioral contact with other students within the context of a game congruent with the rules of such a game. Using appropriate language is defined as the vocalization of words appropriate for the school environment (e.g., no curse words). Following adult directives is defined as the emission of actions as prescribed by a supervising adult.

During the kindergarten recess, paraeducators randomly handed out a total of 20 dollars in each kindergarten zone (7 and 8 ) to students who were observed engaging in behavior consistent with behavior expectations. Similarly during the lunch recesses, the paraeducators in zone 9 had 20 dollars to randomly distribute once every $10 \mathrm{~min}$ to students following expectations (grades 1-5). Students in zone 6 randomly received reward dollars at a frequency of 15 dollars every 10min interval (grades 1-5). As outlined above, the paraeducators were separated across zones, with approximately 1-2 during lunch recess in each zone. The dollars were all delivered based on observation at the scheduled intervals, and it served as a random contingency for reinforcement of appropriate behavior. Thus, not all students following expectations earned a dollar at each interval but had the opportunity to earn one during every recess period.

\section{Results}

The results of the independent group contingency to reduce aggression were analyzed across recess zones and overall effectiveness measured with visual analysis and NAP effect size calculations. Results for the recess and lunch periods are based on baseline data with intervention occurring over a 3-month period (including school holidays). To understand the intervention effectiveness, the two kindergarten recess zones were analyzed in addition to the zones with highest occurrences of aggression for the 1st-5th grades. Figures 1 and 2 display the results of the kindergarten recess (zones 7 and 8). Overall, average rates of aggression decreased across both zones as a result of the intervention. Aggression averaged during 
Fig. 1 Frequency of aggression during kindergarten recess across zones 7 and 8

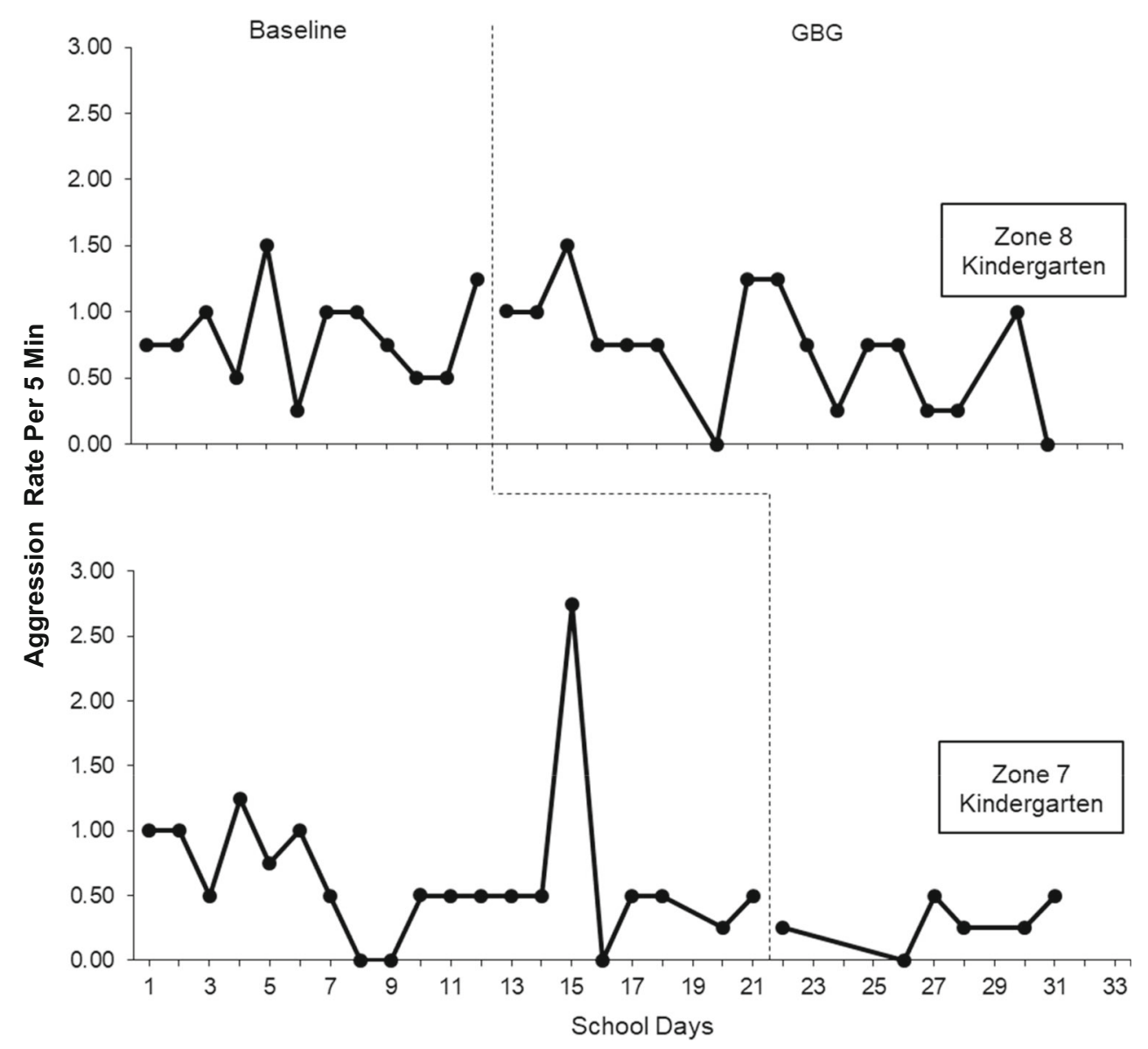

baseline at a rate of 0.81 and 0.65 for zones 8 and 7, respectively. Average rates of aggression decreased to 0.72 and 0.29 for both zones, respectively, as result of the intervention. NAP was calculated by counting the number of pairs showing improvement (lower levels of aggression during intervention) plus half of all ties, divided by all pairs $\mathrm{NAP}=[(\mathrm{Pos}+.5 \mathrm{x}$ Ties) / Pairs]. NAP on a $0-100$ scale for one 8 was .46 and for zone 7 was .80 .

Figures 3 and 5 illustrate the average rate of aggression across both baseline and intervention phases for the two lunch recesses in zone 6 (grades 1-5). Aggression occurred at an average rate of 1.13 and 0.69 during baseline for lunches 1 and 2 , respectively. Rates of aggression notably decreased as a result of the intervention to 0.87 and 0.0 for the respective lunch periods. NAP on a $0-100$ scale for zone 6 lunch 1 was .32 and for lunch 2 was .70 .

Figures 4 and 5 display rates of aggression across both baseline and intervention phases for the two lunch recesses in zone 9 (grades 1-5). Rates of aggression averaged 1.07 and 0.57 during baseline for lunches 1 and 2, respectively.
Fig. 2 Average occurrences of aggression during kindergarten recess across both zones

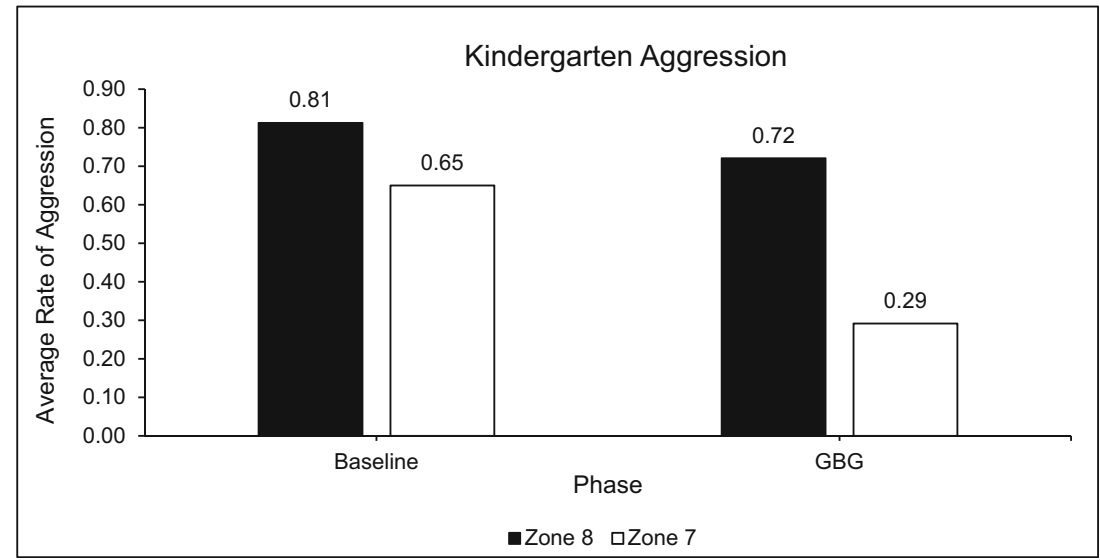


Fig. 3 Frequency of aggression in zone 6 across both lunch recesses

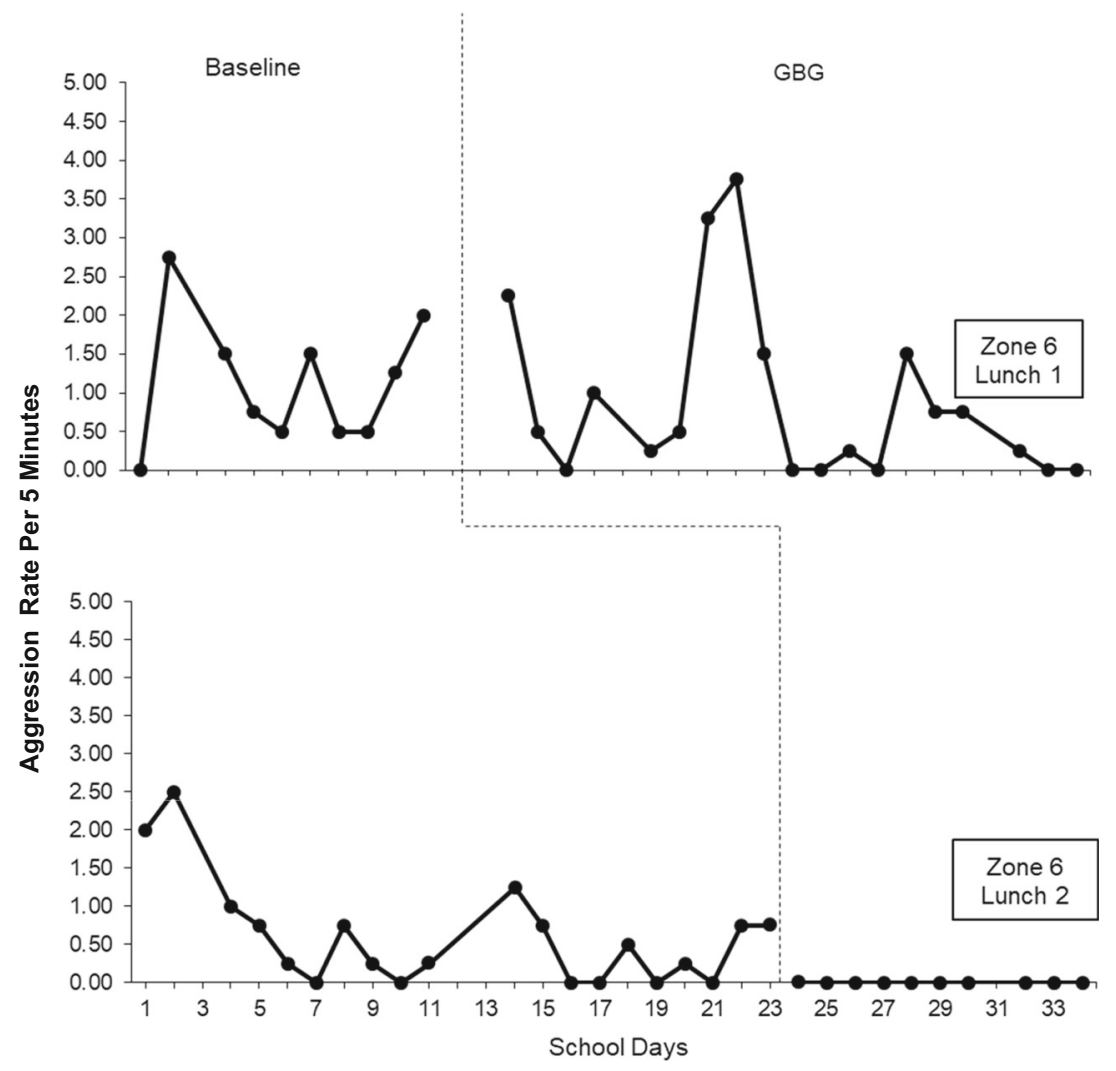

Fig. 4 Frequency of aggression in zone 9 across both lunch recesses

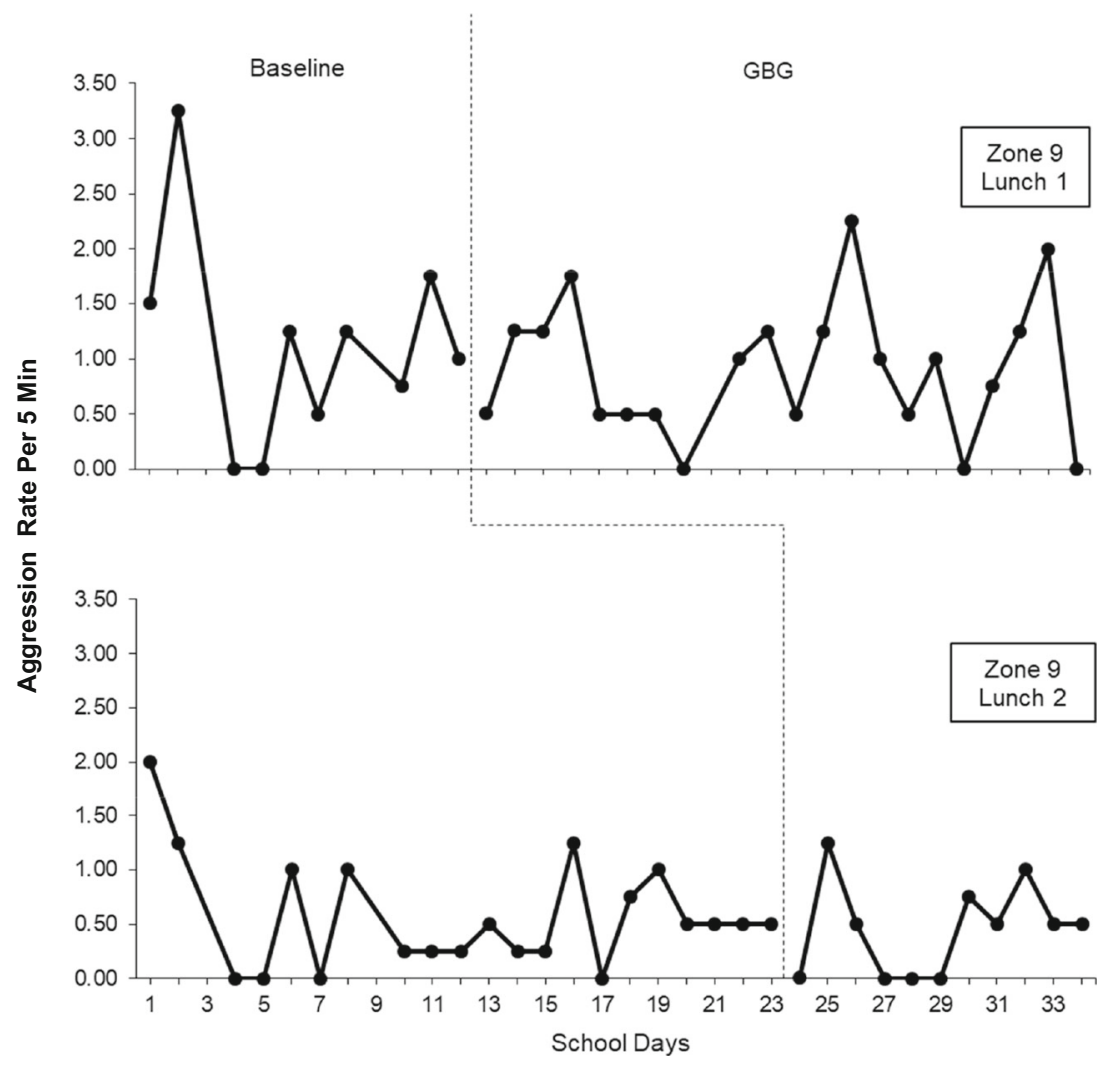


Fig. 5 Average occurrences of aggression in zones 6 and 9 across both lunch recesses
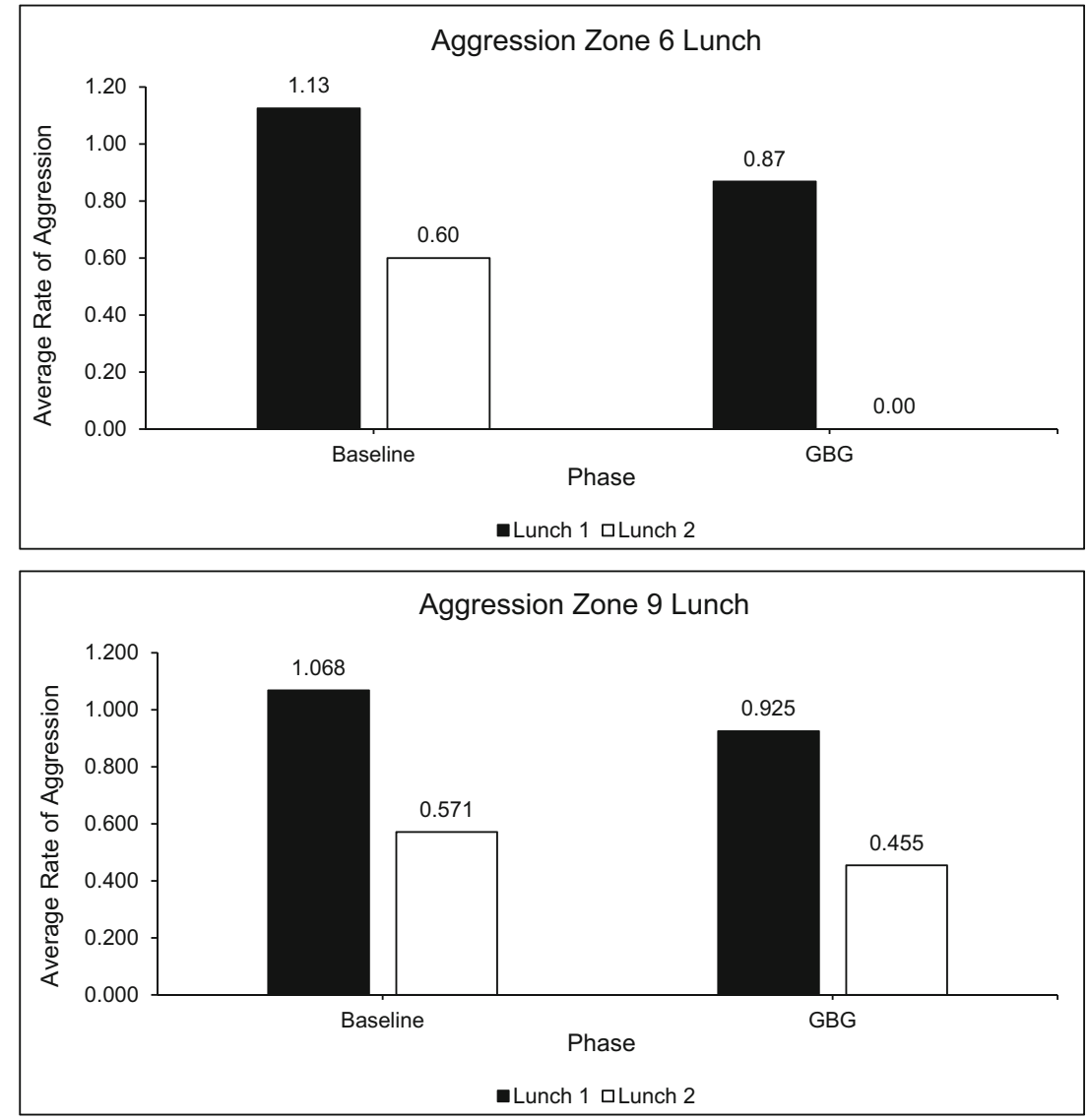

Aggression resulted in a slight decrease as a result of the intervention to 0.93 and 0.46 for both lunches. NAP on a $0-$ 100 scale for zone 9 was .10 and .06 , respectively, for lunch 1 and 2 .

\section{Discussion}

This study aimed to reduce incidents of aggressive behavior across grades K-5th utilizing a randomized token contingency. As recent research has shown, schools that have the most effective school-wide models of PBIS are those that have strong practice level variables (e.g., priority of the district/ school, fidelity of initial implementation, and the capacity of the staff) (McIntosh et al. 2018). In the current sample, there was a clear need from the school site administration for increasing the use of the PBIS initiatives on campus. The initiative of this intervention was designed to train paraeducators with little background in PBIS to collect preliminary data on the use of a reinforcement-based intervention. As a resourcereduction method, students following expectations were randomly provided tokens (as opposed to being given a token at every occurrence). Randomized contingencies have a long line of empirical evidence in school settings and the behavioral literature (e.g., Cariveau and Kodak 2017; Theodore et al.
2004; Kelshaw-Levering et al. 2000). Thus, the use of such a method was beneficial given the size of the student population at any one time in the school yard.

A token economy was conducted in which students were randomly provided reward dollars on a fixed interval schedule during each recess if they were following the positive behavior expectations. This was the first step in developing the Tier 1 reinforcement system for a developing PBIS model. Although previous behavioral research has used formal procedures to determine "randomization" such as drawing a slip of paper, such methods were considered unrealistic to manage considering the high participant count $(+500)$ in large unstructured areas. Therefore, randomization was ensured by paraeducators walking around their respective zones as reward dollars were administered, while at the same time students were in a constant state of motion (e.g., playing with each other). While not an ideal procedure for randomization, it nevertheless helped to ensure that the same students did not receive reward dollars each day.

Findings showed the overall occurrences of aggression decreased during lunch and recess periods across all reported grade levels. The most problematic times observed were during kindergarten recess in which average student aggression was reduced between 30 and $50 \%$ in each zone. However, when considering the effect size, significant effects were seen 
in only one kindergarten zone (zone 7, NAP $=.80$ ). Although significant effects were also observed in zone 6 (grades 1-5, open fields; $\mathrm{NAP}=.70)$, very minimal effects were seen in zone 9 (grades $1-5$ lunch areas; NAP $<.25$ ). While the kindergarten zones (zones 7 and 8) contained less students than the other reported zones (zones 6 and 9), they were also spatially smaller.

Due to the observed differences across the recess zones for the upper grades (first through fifth grades), it was clear that the highest problem areas were also the areas where students gathered in large numbers and dense areas (e.g., zone 6, open field where many ball games are played, and zone 9 , the lunch tables). Because of this trend, the recess aides were recommended to relocate their supervision time and focus to these areas (Lewis et al. 2000). Also, the spatial allocation of aggression by students could be attributed to an understanding of where they could "get away with" certain behaviors compared with the areas where there was a greater likelihood of "being caught." By nature of the token economy, students now needed to shift their aggressive behaviors towards meeting positive behavior expectations in order to receive the school "dollars." As shown in the results of this study, aggressive behaviors for the upper grades were reduced from 50 to $100 \%$ in the open field (zone 6) but were still relatively high in the lunch area (zone 9).

The need for active supervision during the lunch period was clear, and with the number of staff available to cover the entire play areas, it was also apparent that the intervention in zone 9 was insufficient. Further, when it was discovered that many of the students did not have frequent contact with backup reinforcers, as designed, the interpretation of these results then shifts to an understanding of the potential effectiveness of the unpaired tokens and socially mediated reinforcement. Enhancing the frequency of dollar distribution and contingently delivering backup reinforcers (e.g., through a student store) would be obvious modifications to enhance the intervention. It has been well documented that the value of the token is associated with the reinforcers that it can be exchanged for (e.g., backup reinforcer; Bonfonte et al. 2020). However, such reinforcers can become costly in large quantities and groups of individuals, thereby introducing significant practical limitations (e.g., Lott and Jencius 2009; Petry and Bohn 2003). As backup reinforcers can become costly for large groups of students, the need for such resources may dissuade educational agencies from implementing evidencebased interventions. Fiske et al. (2015) examined the effectiveness of a token economy with tokens that did not include a backup reinforcer. Findings showed these "unpaired tokens" resulted in a decrease of behavior and near zero rates of responding for their participants' behaviors. While it has been empirically demonstrated that backup reinforcers are a best practice element to effective token economies with individuals, authors have also shown the efficacy of unpaired tokens in single-case design research (Fiske et al. 2015). To our knowledge, no study has examined the effectiveness of an unpaired token system with a group despite prior research showing the effectiveness of independent group contingencies (e.g., Groves and Austin 2017). Regardless, the effectiveness of the intervention as a whole in this study is apparent and sets up the groundwork for future research to explore the overall effectiveness of unpaired tokens as a preliminary step in school-wide behavior change procedures when resources are limited.

Further, we theorize that the student group responding to the dollars in absence of backup reinforcers could be attributed to socially-mediated contingencies among student members. For example, receiving a dollar may elevate one's "social status" among group peers and allow them to contact additional social contingencies as a result. In addition, students may choose to exchange such dollars among themselves for "favors" or requested actions. Thus, the present results go against traditional knowledge regarding token systems and backup reinforcers, and may serve to open a new avenue of understanding with group behavior.

\section{Limitations}

The data presented in the results reflects a baseline and intervention period across a three month timespan in which the primary investigator was able to pilot the intervention system with the recess paraeducators. However, this was confounded by the limited resources and support for implementation that existed at the time. Although students were told prior to the start of the intervention that they could exchange their dollars for tangible items at the student store, the store was only open once a week after school and students were instructed to "save" their dollars. Thus, the exchanges did not occur frequently and the majority of students earned dollars without backup reinforcers. Due to school closures with Covid-19, no further intervention modifications could be made, but future implementation will require a more refined token economy exchange for certain students. At the end of the intervention period, some of the paraeducators provided feedback that they were dissatisfied with the intervention and expected all aggressive incidents to be remedied. As a result, they indicated they would no longer continue to provide reward dollars after the conclusion of the study. The paraeducators also reported that they did not see the utility behind the reinforcement procedures and felt more comfortable with a punishment-based or response cost system. Aggression as a behavior can be more 
overt and apparent than rule following behaviors. Therefore, instances of aggression may be easier to "catch," identify, and address on a playground with a large number of children to monitor. Furthermore, while punishment often results in an immediate change in behavior, reinforcement-based procedures often require a prolonged period before their effects are observed (Mayer et al. 2019; Thompson and Iwata 2005). The goal was that the observed effects from the intervention would have served as a form of positive reinforcement for staff effort, but it, unfortunately, did not. In recent research, token economies with combined reinforcement and response cost contingencies were more than twice as effective in reducing problem behaviors than a response cost system alone (DeJager et al. 2019). Future directions will incorporate teacher feedback and paraeducator input on the target behaviors for reinforcement as well as a desired outcome for reduced problem behavior (Alberto and Troutman 2017).

It is important to the advancement of the literature to understand which interventions are both liked and disliked by consumers (Schwartz and Baer 1991). Consultation and further training on the use of a token economy, reinforcement procedures, and on token exchanges are essential components in ensuring intervention success and the development of PBIS initiatives. In addition, it is important to understand from a resource standpoint what resources are necessary in the successful implementation of empirically supported behavioral interventions. Having such an understanding could potentially enhance the social validity of such procedures and breakdown misconceptions regarding their use. To note, this intervention was designed to meet the needs of group behavior, similar to class-wide behavior as in a Tier 1 intervention. The goal was to assess the potency of an empirically validated intervention with reduced resources in increasing the number of students meeting behavior expectations. The acceptability for such an intervention was expected to be high, but paraeducators did not report seeing individual behavior change as we observed system-wide changes. It is important for future implementation of the current intervention to understand where it would be permissible to reduce resources (e.g., randomized contingencies, no backup reinforcers) and successfully achieve desired behavioral outcomes. Further, it is important to understand how such a reduction in resources may influence the perception of intervention acceptability and effectiveness among consumers.

Acknowledgments The authors thank the participating school district in the piloting of this intervention study. There is no funding to report.

Availability of Data and Material Data or data collection materials may be requested from the corresponding author or first author of this manuscript.
Code Availability N/A

Author's Contributions The primary author conducted the research study in partnership with the local school district as well as to the written manuscript. The second author contributed to the writing and editing of the manuscript.

Funding This study did not receive any funding.

\section{Declarations}

Conflict of Interest The authors declare that they have no conflict of interest.

\section{References}

Alberto, P. A., \& Troutman, A. C. (2017). Applied behavior analysis for teachers (9th ed.). Pearson.

Astor, R. A., \& Meyer, H. A. (2001). The conceptualization of violenceprone school subcontexts: Is the sum of the parts greater than the whole? Urban Education, 36(3), 374-399. https://doi.org/10.1177/ 0042085901363004.

Barrish, H., Saunders, M., \& Wolf, M. M. (1969). Good behavior game: effects of individual contingencies for group consequences on disruptive behavior in a classroom. Journal of Applied Behavior Analysis, 2(2), 119-124. https://doi.org/10.1901/jaba.1969.2-119.

Behavior Analyst Certification Board. (2014). Professional and ethical compliance code for behavior analysts. Retrieved from http://bacb. com/wp-content/uploads/2015/08/150824-compliance-codeenglish.pdf

Bonfonte, S. A., Bourret, J. C., \& Lloveras, L. A. (2020). Comparing the reinforcing efficacy of tokens and primary reinforcers. Journal of Applied Behavior Analysis, 53(3), 1593-1605. https://doi.org/10. 1002/jaba.675.

Cariveau, T., \& Kodak, T. (2017). Programming a randomized dependent group contingency and common stimuli to promote durable behavior change. Journal of Applied Behavior Analysis, 50(1), 121-133. https://doi.org/10.1002/jaba.352.

Coburn, C. E., Russell, J. L., Kaufman, J. H., \& Stein, M. K. (2012). Supporting sustainability: teachers' advice networks and ambitious instructional reform. American Journal of Education, 119(1), 137182. https://doi.org/10.1086/667699.

Codding, R. S., Livanis, A., Pace, G. M., \& Vaca, L. (2008). Using performance feedback to improve treatment integrity of classwide behavior plans: an investigation of observer reactivity. Journal of Applied Behavior Analysis, 41(3), 417-422. https://doi.org/10.1901/ jaba.2008.41-417.

Colvin, G., Sugai, G., Good, R. H., \& Lee, Y. (1997). Using active supervision and precorrection to improve transition behaviors in an elementary school. School Psychology Quarterly, 12(4), 344-363. https://doi.org/10.1037/h0088967.

Craig, W. M., Pepler, D., \& Atlas, R. (2000). Observations of bullying in the playground and in the classroom. School Psychology International, 21(1), 22-36. https://doi.org/10.1177/ 0143034300211002 .

DeJager, B., Houlihan, D., Filter, K. J., Mackie, P. F. E., \& Klein, L. (2019). Comparing the effectiveness and ease of implementation of token economy, response cost, and a combination condition in rural elementary school classrooms. Journal of Rural Mental Health, 44(1), 39-50. https://doi.org/10.1037/rmh0000123. 
Ennis, C. R., Blair, K. S. C., \& George, H. P. (2015). An evaluation of group contingency interventions: The role of teacher preference. Journal of Positive Behavior Interventions, 18(1), 17-28. https:// doi.org/10.1177/1098300715577663.

Fabiano, G. A., Reddy, L. A., \& Dudek, C. M. (2018). Teacher coaching supported by formative assessment for improving classroom practices. School Psychology Quarterly, 33(2), 293-304. https://doi.org/ $10.1037 / \mathrm{spq} 0000223$.

Fiske, K. E., Isenhower, R. W., Bamond, M., Delmolino, L., Sloman, K. N., \& LaRue, R. H. (2015). Assessing the value of token reinforcement for individuals with autism. Journal of Applied Behavior Analysis, 48(2). https://doi.org/10.1002/jaba.207.

Floress, M. T., Beschta, S. L., Meyer, K. L., \& Reinke, W. M. (2017). Praise research trends and future directions: Characteristics and teacher training. Behavioral Disorders, 43(1), 227-243. https://doi. org/10.1177/0198742917704648.

Galbraith, L. A., \& Normand, M. P. (2017). Step it up! Using the good behavior game to increase physical activity with elementary school students at recess. Journal of Applied Behavior Analysis, 50(4), 856-860. https://doi.org/10.1002/jaba.402.

Gaughan, E., \& Axelrod, S. (1989). Behavior and achievement relationships with emotionally disturbed children: An applied study. Psychology in the Schools, 26, 89-99. https://doi.org/10.1002/ 1520-6807(198901)26:189::AID-PITS23102601133.0.CO;2-W.

Glenn, S. S., \& Malott, M. E. (2004). Complexity and selection: ismplications for organizational change. Behavior and Social Issues, 13(2), 89-106. https://doi.org/10.5210/bsi.v13i2.378.

Groves, E. A., \& Austin, J. L. (2017). An evaluation of interdependent and independent group contingencies during the good behavior game. Journal of Applied Behavior Analysis, 50(3), 552-566. https://doi.org/10.1002/jaba.393.

Horner, R. H., Sugai, G., Smolkowski, K., Eber, L., Nakasato, J., Todd, A., \& Esperanza, J. (2009). A randomized, waitlist-controlled effectiveness trial assessing school-wide positive behavior support in elementary schools. Journal of Positive Behavior Interventions, 11(3), 133-144. https://doi.org/10.1177/1098300709332067.

Ivy, J. W., Meindl, J. M., Overley, E., \& Robson, K. M. (2017). Token economy: A systematic review of procedural descriptions. Behavior Modification, 41(5), 708-737. https://doi.org/10.1177/ 0145445517699559.

Jung, J., Suroto, F., \& Y., \& Takahashi, T. (2005). The effects of group contingency strategy on students' behaviors in physical education classes in Korea using multiple baseline design. International Journal of Sport and Health Science, 3, 46-56. https://doi.org/10. 5432/ijshs.3.46.

Kelshaw-Levering, K., Sterling-Turner, H. E., Henry, J. R., \& Skinner, C. H. (2000). Randomized interdependent group contingencies: group reinforcement with a twist. Psychology in the Schools, 37(6), 523533. https://doi.org/10.1002/1520-6807(200011)37:6\%3C523:: AID-PITS5\%3E3.0.CO;2-W.

Krispin, J. (2017). Positive feedback loops of metacontingencies: a new conceptualization of cultural-level selection. Behavior and Social Issues, 26(1), 95-110. https://doi.org/10.5210/bsi.v26i0.7397.

Lewis, T. J., Colvin, G., \& Sugai, G. (2000). The effects of precorrection and active supervision on the recess behavior of elementary students. Education and Treatment of Children, 23(2), 109-121.

Lott, D. C., \& Jencius, S. (2009). Effectiveness of very low-cost contingency management in a community adolescent treatment program. Drug and Alcohol Dependence, 102(1-3), 162-165. https://doi.org/ 10.1016/j.drugalcdep.2009.01.010.

Mayer, G. R., Sulzer-Azaroff, B., \& Wallace, M. (2019). Behavior analysis for lasting change (4th ed.). Cornwall-on-Hudson: Sloan Publishing.
McCurdy, B. L., Lannie, A. L., \& Barnabas, E. (2009). Reducing disruptive behavior in an urban school cafeteria: an extension of the good behavior game. Journal of School Psychology, 47(1), 39-54. https:// doi.org/10.1016/j.jsp.2008.09.003.

McGoey, K. E., \& DuPaul, G. J. (2000). Token reinforcement and response cost procedures: reducing the disruptive behavior of preschool children withattention-deficit/hyperactivity disorder. School Psychology Quarterly, 15, 330-343. https://doi.org/10.1037/ h0088790.

McIntosh, K., Mercer, S. H., Nese, R. N. T., Strickland-Cohen, M. K., Kittelman, A., Hoselton, R., \& Horner, R. H. (2018). Factors predicting sustained implementation of a universal behavior support framework. Educational Research, 47(5), 307-316. https://doi.org/ 10.3102/0013189X187776975.

Mesa, J., Lewis-Palmer, T., \& Reinke, W. (2005). Providing teachers with performance feedback on praise to reduce student problem behavior. Beyond Behavior, 15(1), 3-7 http://www.ccbd.net/ content/providing-teachers-performance-feedback-praise-reducestudent-problem-behavior.

Murphy, K. A., Theodore, L. A., Aloiso, D., Alric-Edwards, J. M., \& Hughes, T. L. (2007). Interdependent group contingency and mystery motivators to reduce preschool disruptive behavior. Psychology in the Schools, 44(1), 53-63. https://doi.org/10.1002/pits.20205.

Parker, R. I., \& Vannest, K. (2009). An improved effect size for singlecase research: Nonoverlap of all pairs. Behavior Therapy, 40(4), 357-367. https://doi.org/10.1016/j.beth.2008.10.006.

Petry, N. M., \& Bohn, M. J. (2003). Fishbowls and candy bars: using lowcost incentives to increase treatment retention. Science \& Practice Perspectives, 2(1), 55-61. https://doi.org/10.1151/spp032155.

Schwartz, I. S., \& Baer, D. M. (1991). Social validity assessments: is current practice state of the art? Journal of Applied Behavior Analysis, 24(2), 189-204. https://doi.org/10.1901/jaba.1991.24189.

Shih, W., Dean, M., Kretzmann, M., Locke, J., Senturk, D., Mandell, D. S., Smith, T., \& Kasari, C. (2019). Remaking recess intervention for improving peer interactions at school for children with autism spectrum disorder: multisite randomized trial. School Psychology Review, 48(2), 133-144. https://doi.org/10.17105/SPR-2017-0113. V48-2.

Soares, D. A., Harrison, J. R., Vannest, K. J., \& McClelland, S. S. (2016). Effect size for token economy use in contemporary classroom settings: a meta-analysis of single-case research. School Psychology Review, 45(4), 379-399. https://doi.org/10.17105/SPR45-4.379399.

Sugai, G., \& Horner, R. H. (2002). The evolution of discipline practices: school-wide positive behavior supports. Child and Family Behavior Therapy, 24(1-2), 23-50. https://doi.org/10.1300/J019v24n01_03.

Swain-Bradway, J., Lindstrom Johnson, S., Bradshaw, C., \& McIntosh, K. (2017). What are the economic costs of implementing SWPBIS in comparison to the benefits from reducing suspensions? (PBIS evaluation brief). Eugene: OSEP TA Center on Positive Behavioral Interventions and Supports.

Theodore, L., Bray, M. A., \& Kehle, T. J. (2004). A comparative study of group contingencies and randomized reinforcers to reduce disruptive classroom behavior. School Psychology Quarterly, 19(3), 253271. https://doi.org/10.1521/scpq.19.3.253.40280.

Thompson, R. H., \& Iwata, B. A. (2005). A review of reinforcement control procedures. Journal of Applied Behavior Analysis, 38(2), 257-278. https://doi.org/10.1901/jaba.2005.176-03.

Wahl, E., Hawkins, R. O., Haydon, T., Marsicano, R., \& Morrison, J. Q. (2016). Comparing versions of the good behavior game: can a positive spin enhance effectiveness? Behavior Modification, 40(4), 493-517. https://doi.org/10.1177/0145445516644220. 
Wolery, M., Bailey, D. B., \& Sugai, G. (1988). Effective teaching: Principles and procedures of applied behavior analysis with exceptional students. Boston: Allyn \& Bacon.

Wolfe, V. V., Boyd, L. A., \& Wolfe, D. A. (1983). Teaching cooperative play to behavior problem preschool children. Education and Treatment of Children, 6, 1-9.

Wright, R. A., \& McCurdy, B. L. (2011). Class-wide positive behavior support and group contingencies: examining a positive variation of the good behavior game. Journal of Positive Behavior Interventions, 14(3), 173-180. https://doi.org/10.1177/1098300711421008.

Publisher's Note Springer Nature remains neutral with regard to jurisdictional claims in published maps and institutional affiliations.
Jordan Yassine earned dual master's degrees from California State University, Los Angeles in school psychology and applied behavior analysis. As a behaviorally-oriented school psychologist, his research interests are broad as he seeks to incorporate information across the sciences towards understanding contextual behavioral processes in schools.

Leigh Ann Tipton-Fisler is a faculty member at California State University, Los Angeles in the Division of Special Education and Counseling. Her primary research interests include professional development for teachers and parents on supporting transition needs for youth with developmental disabilities. She also works with local school districts to provide consultation for teachers and school psychologists to improve systems-level change for at-risk youth. 